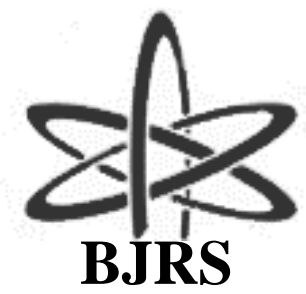

\author{
BRAZILIAN JOURNAL \\ $\mathrm{OF}$ \\ RADIATION SCIENCES \\ 06-02-B (2018) 01-12
}

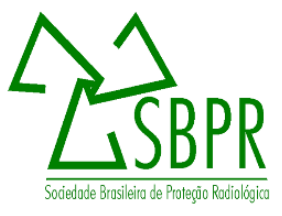

\title{
Ações de proteção radiológica no recolhimento de material radioativo descartado indevidamente
}

\author{
Neri $^{a}$ E. P. M., Da Silva ${ }^{a}$ F. C. A. \\ ${ }^{a}$ Instituto de Radioproteção e Dosimetria/CNEN, 22783-127, Avenida Salvador Allende s/n, Barra da Tijuca, Rio de \\ Janeiro-RJ, Brasil \\ dasilva@ird.gov.br
}

\section{RESUMO}

O Brasil possui, atualmente, 1729 instalações radiativas que usam fontes de radiação nos seus processos e são controladas pela CNEN através de normas, autorizações e inspeções. Esses materiais radioativos, usados tanto na área médica, indústria, pesquisa, comércio, entre outras, são algumas vezes descartados e encontrados em locais inadequados, tais como, lixões, lixo industrial, ruas, praças, podendo, assim, serem encontrados por profissionais de limpeza urbana sem o devido conhecimento dos mesmos. Este trabalho apresenta as ações de proteção radiológica necessárias para a identificação e recolhimento de material radioativo visando prevenir a exposição desnecessária dos profissionais de limpeza. As ações estão baseadas nos princípios, guias e normas de proteção radiológica. De acordo com o tipo de material radioativo as principais ações de proteção radiológica são, entre outras: reconhecimento de um material radioativo; uso correto de equipamento de proteção individual para conter possível contaminação radiológica; uso de um monitor de radiação; implementação de um controle de área; etc. Para que as ações de proteção radiológica, na identificação e recolhimento de material radioativo descartado sejam eficazes, há necessidade de implementar um programa de treinamento em proteção radiológica para os profissionais de limpeza urbana de maneira que não se exponham desnecessariamente, até a chegada de um perito em proteção radiológica da CNEN que providencie o recolhimento seguro deste material.

Palavras-chave: Proteção radiológica; material radioativo descartado; profissionais de limpeza urbana. 


\begin{abstract}
Brazil has 1729 radioactive facilities that use radiation sources in their processes and controlled by CNEN through regulations, authorizations and inspections. These radioactive materials used in medical, industry, research and commerce areas are sometimes discarded and found in inappropriate places, such as, garbage dumps, industrial waste, streets and squares. Sometimes these radioactive materials can be found by urban cleaning professionals without the proper knowledge. This work presents the radiation protection actions necessary for the identification and recovery of radioactive material in order to prevent unnecessary exposure of street cleaners. The actions are based on the principles, guidelines and standards of radiological protection. According to the type of radioactive material the main actions of radiation protection are: recognition of radioactive material; correct use of personal protective equipment; use of radiation monitor; implementation of area control; etc. For the effectiveness of radiation protection actions, a training program for street cleaning should be implemented to avoid radiation exposure until safe recovery of the radioactive material by the CNEN specialist.
\end{abstract}

Keywords: Radiation protection; discarded radioactive material; street cleaner.

\title{
1. INTRODUÇÃO
}

Com o aumento da população cria-se uma maior na produção de lixo e, consequentemente, torna-se um desafio estabelecer um local ideal para a disposição final de resíduos. Sendo a limpeza urbana de extrema importância, tanto para a saúde do homem quanto para o meio ambiente, é cada vez mais necessária a preocupação com a disposição adequada de resíduos. Quando se fala em lixo, deve-se ressaltar que o mesmo passa por algumas etapas entre sua geração e a disposição final adequada. Estas etapas compreendem: o acondicionamento; a coleta realizada por caminhões com um sistema de compactação do lixo; a transferência do lixo dos caminhões para carretas e; a destinação para disposição final [1]. Para isto, a Cidade do Rio de Janeiro possui a maior empresa pública de limpeza urbana da América Latina, a Companhia Municipal de Limpeza Urbana COMLURB, cujas atividades vão desde a coleta de lixo domiciliar até a disposição final, incluindo a limpeza de áreas públicas, logradouros e hospitais municipais [2]. Estas atividades são executadas pelos profissionais de limpeza urbana, os garis, ilustrados na figura 1. 
Figura 1: Garis da COMLURB em serviço.

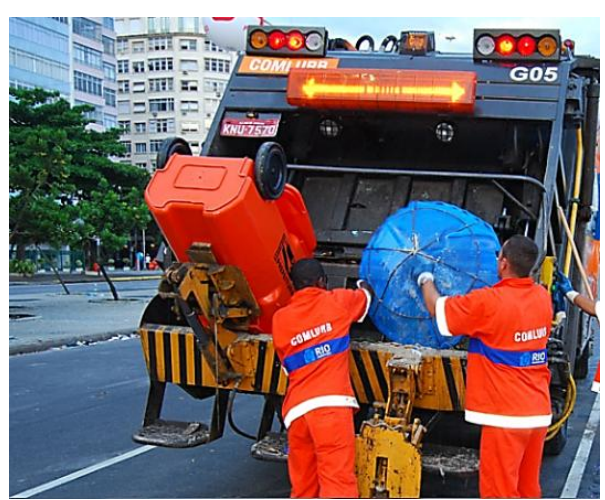

Fonte: PREFEITURA DO RIO DE JANEIRO

Dentre todo tipo de resíduos desprezados em lixões, terrenos baldios ou até nas ruas pode haver lixo doméstico, industrial e, até mesmo, materiais radioativos descartados de maneira indevida. Caso um gari encontre um material radioativo durante suas atividades de trabalho é provável que se exponha a radiação, se contamine ou ainda, que afete toda uma comunidade, por não ter conhecimento sobre proteção radiológica voltado para sua atividade.

No Brasil, o licenciamento das instalações radiativas é realizado pela Comissão Nacional de Energia Nuclear (CNEN), que é a Autoridade Reguladora. Segundo a CNEN, atualmente, há um total de 1729 autorizadas que utilizam material radioativo ou geradores de radiação, sendo que, cerca de $58 \%$ estão localizadas na região Sudeste do país [3].

Estas instalações radiativas utilizam fontes de radiação ionizante em diversas áreas, tais como: na medicina (radioterapia, medicina nuclear, etc.), na indústria (gamagrafia industrial, medidores nucleares, traçadores radioativos, etc.), em pesquisas (agricultura, alimentos, etc.), no comércio (para-raios radioativo, fontes testes, etc.), entre outras. Quando estas fontes radioativas deixam de ser úteis devem ser descartadas de forma adequada visando a proteção das pessoas e do meio ambiente.

A periculosidade das fontes radioativas é estabelecida pela CNEN, baseada na Categorização de Fontes recomendada pela Agência Internacional de Energia Atômica (AIEA), onde é levado em consideração a atividade da fonte e os possíveis efeitos da radiação. Práticas e fontes radioativas são, então, classificadas em 5 níveis, onde a Categoria 1 é a mais perigosa e a Categoria 5 é a menos perigosa. Por exemplo, as fontes usadas em radioterapia são classificadas como Categoria 1; as 
fontes de gamagrafia industrial são Categoria 2; as fontes de medidores nucleares são Categoria 3 ou 4 ; etc. [4].

Apesar de o controle exercido pelas Autoridades Reguladoras, vários fatos envolvendo materiais radioativos extraviados, de diversas Categorias, foram divulgados, através de meios de comunicação tanto no Brasil como no exterior, relatando o encontro de fontes abandonadas, descartadas de forma inapropriada ou rejeitadas inadequadamente.

Um exemplo foi um caso ocorrido com um para-raios radioativo contendo amerício-241 que foi localizado por um pedreiro em um terreno em obra no Distrito Federal. A área foi isolada pelos Bombeiros e a Polícia Militar até a chegada de técnicos da CNEN (figura 2) [5].

Figura 2: Notícia sobre para-raios radioativo encontrado em obra no DF.

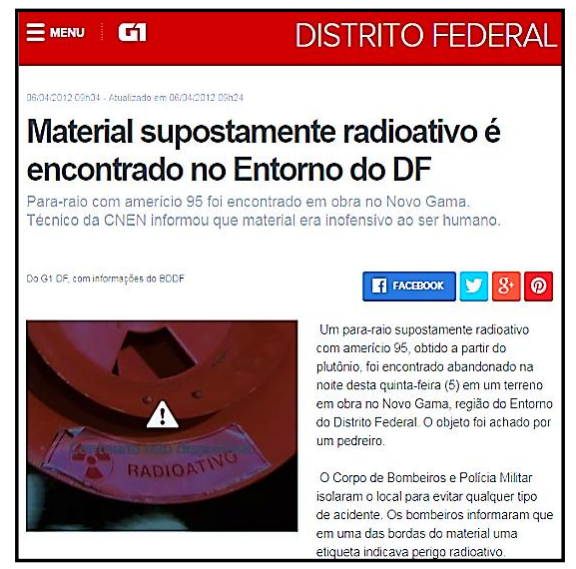

Fonte: G1

Um dos problemas é que, caso um gari encontre um material radioativo descartado inadequadamente em via pública, é provável que este material siga o trajeto que um resíduo comum segue normalmente, podendo causar dano a pessoas ou ao meio ambiente. O fluxograma, apresentado na figura 3, ilustra o possível caminho a se realizado pelo material radioativo. 
Figura 3: Fluxograma do trajeto do lixo até a disposição final.

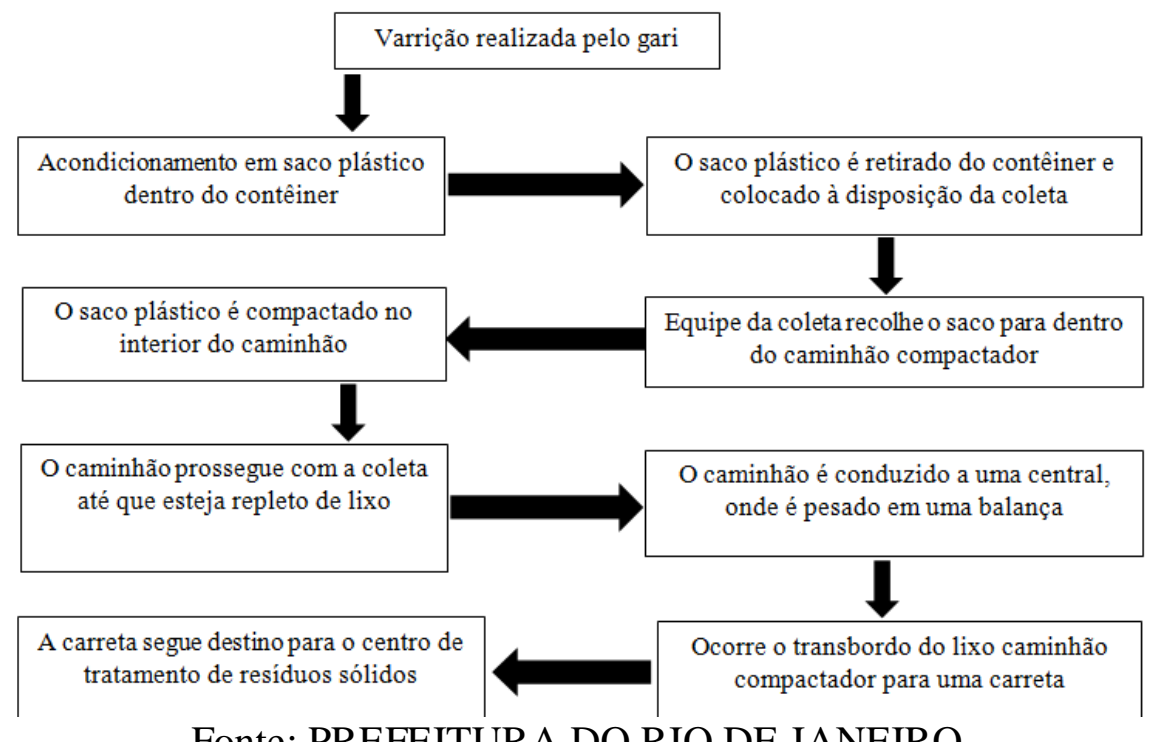

Fonte: PREFEITURA DO RIO DE JANEIRO

Analisando o percurso, desde a varrição até a disposição final, é possível ter uma noção de que o número de pessoas expostas pode ser bastante alto, caso um material radioativo for descartado inadequadamente. Além disso, os profissionais que trabalham no caminhão recolhedor de lixo ficariam expostos por um tempo prolongado, até que fosse necessário o transbordo dos resíduos coletados.

Para que seja possível a identificação de materiais radioativos pelos garis, tendo em vista que não dispõem de detectores de radiação, é importante apresentar aos mesmos o símbolo internacional da presença de radiação ionizante, assim como a etiqueta de embalados utilizados para o transporte destes materiais e a sinalização dos veículos utilizados para estes transportes; além de mostrar a estes trabalhadores imagens de materiais e equipamentos com fontes radioativas que mais são extraviadas ou descartadas divulgadas na mídia como, por exemplo, irradiadores de gamagrafia (e seu porta-fonte) e para-raios radioativos.

Existem diversas recomendações internacionais, legislações e normas brasileiras sobre o descarte adequado de materiais radioativos visando à proteção das pessoas e do meio ambiente. As principais são: a recomendação da IAEA, General Safety Guide - GSG No.1 - Classification of Radioactive Waste [6]; a Posição Regulatória CNEN NN-3.01/001: 2011 que estabelece os 
critérios de exclusão, isenção e dispensa dos requisitos de proteção radiológica [7] e a norma CNEN NN-8.01 Gerência de Rejeitos Radioativos de Baixo e Médio Níveis de Radiação de abril de 2014 [8]. Além de resoluções dos Ministérios do Meio Ambiente e da Saúde que abordam o descarte adequado destes materiais $[9,10]$.

Este trabalho tem como objetivo apresentar as ações de proteção radiológica necessárias para a identificação segura de material radioativo a ser realizada pelos garis. Além de demonstrar a necessidade de implementar um treinamento em proteção radiológica para estes profissionais.

\section{MATERIAIS E MÉTODOS}

Este estudo foi baseado na observação das atividades laborativas de profissionais de limpeza urbana durante os anos atuação da autora na área de limpeza, tendo por base o possível trajeto de um material radioativo como se fosse um resíduo comum. Essas observações foram relacionadas com evidências de materiais radioativos encontrados que foram descartados de maneira inapropriada e divulgadas na mídia.

Foi realizada uma detalhada revisão bibliográfica sobre eventos acontecidos, os riscos de fontes radioativas e as ações baseadas nos princípios, guias e normas de proteção radiológica relacionados ao descarte de materiais radioativos.

Foi realizada, também, uma pesquisa, através de entrevista presencial, com garis e os seus gerentes para avaliar o nível de informação dos mesmos com relação a materiais radioativos. Nesta pesquisa foram entrevistados 21 garis e 2 gerentes, onde foram utilizados 2 questionários sendo um para os garis e o outro para os gerentes. Cada questionário era composto por três perguntas relacionadas na figura 4 . 
Figura 4: Questionários utilizados na metodologia.

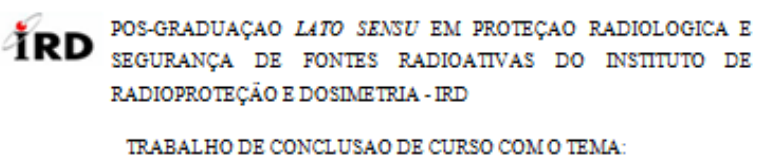

AÇÖES DE PROTEÇÄO RADIOL OGICA NO RECOLHMIENTO DE NAATERIAL RADIOATVO DESCARTADO INDEVIDAMENTE

QUESTIONARIO PARA A METODOLOGIA DIRECIONADO AOS GARIS

NOME:
\begin{tabular}{|c|c|c|}
\hline QUESTAO & PERGUNTA & RESPOSTA \\
\hline 1- & $\begin{array}{c}\text { O que você costuma fazer quando } \\
\text { encontra objetos matalicos jogados na } \\
\text { rua durante seu trabalho? }\end{array}$ & \\
\hline 2- & Você conhece estes objetos? & Sim ( ) ou Näo( ). \\
\hline $3-$ & Você conhece este simbolo? & \\
\hline
\end{tabular}

İRD POS-GRADUAÇAO LATO SENSU EM PROTEÇAO RADIOLOGICA E SEGURANÇA DE FONTES RADIOATVAS DO INSTITUTO DE RADIOPROTEÇÄO E DOSLETRIA - IRD

TRABALHO DE CONCLUSAO DE CURSO COM O TEMCA:

AÇÖES DE PROTEÇÄO RADIOLOGICA NO RECOLHMENTO DE NCATERIAI RADIOATVO DESCARTADO INDEVIDAMENTE

QUESTIONARIO PARA A METODOLOGIA DIRECIONADO AOS GERENTES

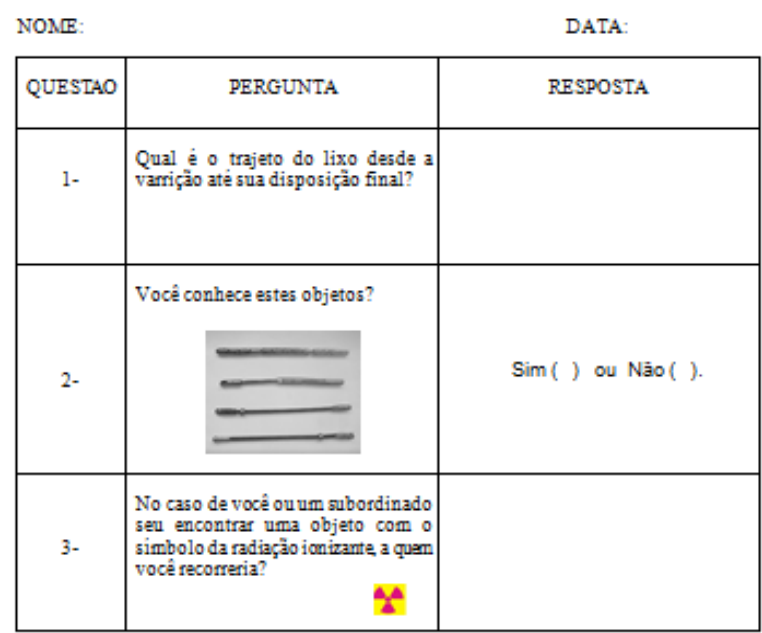

Fonte: Os autores

\section{RESULTADOS E DISCUSSÃO}

Com relação às entrevistas com os garis, embora 19 dos participantes tenham reconhecido o símbolo internacional das radiações ionizantes, praticamente todos os 21 não reconheceram os porta-fontes utilizados em gamagrafia industrial, que é de alto risco radiológico. O único que disse conhecer não soube explicar do que se tratava. Além disso, quando questionados sobre o que fariam se encontrassem esse tipo de metal durante seu trabalho, 17 dos participantes responderam que descartariam dentro do saco de lixo com o qual trabalham, 2 participantes o deixariam no mesmo local, 1 participante não soube explicar e 1 participante afirmou que venderia no ferro-velho.

$\mathrm{Na}$ entrevista com os gerentes, os dois participantes descreveram o trajeto do lixo como sendo que o mesmo seria ensacado e recolhido pelo caminhão da coleta para ser levado ao aterro sanitário. 
Sendo que um deles mencionou que o lixo é conduzido até uma estação de transferência de resíduos para depois ser levado ao aterro sanitário. Entretanto, nenhum dos dois reconheceu os porta-fontes. E com relação à questão sobre a quem recorreriam em caso de encontrarem algum objeto com o símbolo de radiação ionizante, um dos participantes acionaria a defesa civil e a sua diretoria e o outro participante telefonaria para o gerente do aterro sanitário em busca de informações.

O gari deve saber como deve agir caso se depare com material radioativo, o que poderá ser possível através de treinamento sobre proteção radiológica voltado para a função que desempenha, que contenha tópicos sobre como identificar o símbolo internacional de presença da radiação ionizante, conhecer as fontes de radiação ionizante que se extraviam com maior frequência, ter noções dos efeitos nocivos que a manipulação incorreta destes materiais pode causar. O ideal é que o treinamento referido seja ministrado utilizando uma linguagem clara e objetiva.

As ações de proteção radiológica no recolhimento de um material radioativo descartado indevidamente apresentadas neste estudo podem ser classificadas como ações primárias e ações de emergência, que devem ser do conhecimento dos profissionais de limpeza urbana [11].

As ações primárias referem-se às primeiras medidas de proteção radiológica realizadas pelo profissional que localizou o material radioativo. São elas:

$1^{\mathrm{a}}$ : Reconhecer o objeto.

O objeto localizado poderá ser reconhecido através do símbolo internacional da radiação ionizante nele contido ou ainda por fotos dos materiais radioativos mais suscetíveis ao seu extravio como para-raios radioativos, porta-fontes de gamagrafia, entre outros.

$2^{\mathrm{a}}$ : Manter-se a distância.

O trabalhador deverá manter-se a distância para que a exposição seja reduzida com o inverso do quadrado da distância.

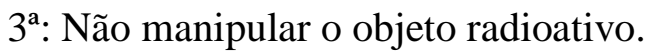

Ainda que esteja usando luvas, o profissional não deverá manipular o objeto radioativo. Em hipótese alguma deverá tentar comercializar o artefato sob o risco de provocar danos biológicos em si próprio e nas demais pessoas que tiverem contato ou mesmo se manterem próximas próximos a ele.

$4^{\mathrm{a}}$ : Não tentar realizar o resgaste do material radioativo. 
O profissional que localizar o material radioativo não deverá tentar realizar seu resgate, pois esta é uma tarefa a ser realizada por especialistas em emergências radiológicas. Caso uma pessoa despreparada e sem os equipamentos necessários o faça, poderá estar sujeita a danos severos.

$5^{\mathrm{a}}$ : Rapidez na resposta à emergência.

A emergência deve ser respondida o mais breve possível para evitar que o risco de exposição se potencialize e os níveis de doses aumentem com o decorrer do tempo.

$6^{\text {a }}$ : Não ser omisso.

A perda de controle de uma fonte de radiação ionizante é uma situação crítica que requer uma resposta visando proteger o homem e o meio ambiente de seus efeitos nocivos. Se esta emergência for ignorada, as pessoas poderão sofrer danos de forma direta ou através do meio ambiente em que está inserido. Por isso, a importância de notificar a ocorrência.

$7^{\mathrm{a}}$ : Notificar o seu superior.

O superior deverá ser comunicado de forma clara e detalhada através de um canal eficaz.

$8^{\mathrm{a}}$ : Notificar a CNEN.

O profissional terá acesso a um canal de comunicação eficaz ao órgão responsável pelo resgate do dispositivo radioativo de forma direta ou indireta, ou seja, através de seu superior imediato.

9a: Solicitar auxílio.

Autoridades como, a polícia, os bombeiros, a defesa civil, entre outras podem ser solicitadas para isolar a área e afastar curiosos sem causar pânico.

$10^{\mathrm{a}}$ : Aguardar a chegada da equipe de emergências radiológicas da CNEN.

É importante que o trabalhador envolvido aguarde a equipe especializada que se responsabilizará por reconhecimento do material radioativo, a fim de prestar informações importantes relacionadas ao fato.

Os profissionais de limpeza urbana devem ter informações gerais sobre as ações de emergência, que serão realizadas por especialistas da área, para uma colaboração eficaz. Dentre elas, destacamse:

$1^{\mathrm{a}}$. Atendimento à notificação.

Após o grupo de emergência de plantão da CNEN receber o contato do solicitante, fará algumas perguntas pertinentes ao caso e irá atendê-lo. O grupo seguirá para o local informado levando 
monitores portáteis de radiação, monitores individuais, equipamentos de proteção individual e coletivo, entre outros, adequados para uma resposta eficaz à emergência em questão.

$2^{\mathrm{a}}$. Análise do evento da emergência.

Ao chegar ao local indicado, o grupo de resposta a emergência vai analisar a situação, realizar levantamento radiométrico, estabelecer/confirmar a distância do isolamento e verificar a integridade da fonte radioativa.

$3^{\mathrm{a}}$. Entrevista com o profissional que localizou o material radioativo.

Ao questionar o indivíduo que localizou o material radioativo será possível obter informações importantes sobre o evento. Estas informações servirão como um guia para proceder de forma adequada na resposta a emergência, por exemplo, se há possibilidade de contaminação no local e de pessoas, os envolvidos e as circunstâncias.

$4^{\mathrm{a}}$. Recolhimento do material radioativo descartado

A equipe de emergência fará o resgate do material radioativo seguindo os requisitos de proteção radiológica, delimitando e sinalizando as áreas, utilizando luvas e outros equipamentos de proteção individual, bem como materiais para resgate em emergências, por exemplo, pinças longas, placas de chumbo para reduzir a exposição dos profissionais de envolvidos no resgate, contêineres para transporte de fontes dependendo da geometria da fonte em questão, etc.

$5^{\mathrm{a}}$. Destinação do material radioativo recolhido

Dependendo da classificação do material radioativo resgatado, ele será destinado a um depósito dos institutos da CNEN ou disposto como resíduo não perigoso caso seja isento ou dispensável segundo controle regulatório.

\section{CONCLUSÕES}

Foi verificado que o descarte de material radioativo em lugares públicos é uma realidade e que há necessidade de os profissionais de limpeza urbana terem um conhecimento específico para proceder de forma segura o reconhecimento e recolhimento desse material radioativo descartado. Para tal, é fundamental implementar um programa de treinamento em proteção radiológica para os profissionais de limpeza urbana, de forma que as ações sejam eficazes para proteger as pessoas e o 
meio ambiente. Recomenda-se que, para a identificação de material radioativo, seja elaborado pôsteres ou folders contendo o símbolo internacional da radiação ionizante e imagens de equipamentos e fonte que se extraviam com a maior frequência como para-raios radioativos, medidores nucleares portáteis, irradiadores de gamagrafia e seus porta-fontes, frascos de radiofármacos utilizados em medicina nuclear, entre outros.

Recomenda-se, também, que a COMLURB disponha, nas estações de transferência de resíduos, de um portal com monitor de radiação na entrada dos caminhões que irão realizar o transbordo do lixo coletado, bem como monitor portátil de radiação e profissionais treinados para uma identificação imediata do material radioativo.

\section{REFERÊNCIAS}

[1] CUNHA, V.; FILHO, J. V. C. Gerenciamento da Coleta de Resíduos Sólidos Urbanos: Estruturação e Aplicação de Modelo Não-Linear de Programação por Metas. Gestão e Produção. v.9, n. 2, p. 143-161, 2002.

[2] PREFEITURA DA CIDADE DO RIO DE JANEIRO. Companhia Municipal de Limpeza Urbana - COMLURB. Disponível em: <www.prefeitura.rio/web/comlurb/exibeconteudo?id=1771922>. Último acesso: 14 Jun. 2017.

[3] CNEN - Comissão Nacional de Energia Nuclear. Instalações Autorizadas. Disponível em: <www.cnen.gov.br/instalacoes-autorizadas>. Último acesso: 20 Set. 2017a.

[4] IAEA - International Atomic Energy Agency. Categorization of radioactive sources. IAEATECDOC-1344. Vienna, 2003.

[5] G1. Material supostamente radioativo é encontrado no Entorno do DF. Disponível em: <g1.globo.com/distrito-federal/noticia/2012/04/material-supostamenteradioativo-e-encontradono-entorno-do-df.html>. Último acesso: 04 Jul. 2017.

[6] IAEA - International Atomic Energy Agency. Classification of Radioactive Waste. General Safety Guide - GSG N 1. Vienna, 2009. 
[7] CNEN - Comissão Nacional de Energia Nuclear. Critérios de Exclusão, isenção e Dispensa de Requisitos de Proteção Radiológica. Posição regulatória 3.01/001, 2011.

[8] CNEN - Comissão Nacional de Energia Nuclear. Normas técnicas. Disponível em: <www.cnen.gov.br/normas-tecnicas>. Último acesso: 26 Ago. 2017 b.

[9] ANVISA - Agência Nacional de Vigilância Sanitária. Resolução RDC No 306, DE 7 DE DEZEMBRO DE $2004 . \quad$ Disponível em:<portal.anvisa.gov.br/documents/33880/2568070/res0306_07_12_2004.pdf/95eac678-d4414033-a5ab-f0276d56aaa6>. Último acesso: 06 Set. 2017.

[10] CONAMA - Conselho Nacional do Meio Ambiente. Resolução No 358, DE 29 DE ABRIL DE 2005. Disponível em: <www.mma.gov.br/port/conama/res/res05/res35805.pdf>. Último acesso: 06 Set. 2017.

[11] NERI, E. P. M. Ações de Proteção Radiológica no Recolhimento de Material Radioativo Descartado. Monografia Pós-Graduação IRD, Rio de Janeiro, 2017. 